\title{
Custo do ensino de graduação em instituições federais de ensino superior: 0 caso da Universidade Federal de Viçosa*
}

\author{
Elizete Aparecida de Magalhães** \\ Suely de Fátima Ramos Silveira*** \\ Luiz Antônio Abrantes**** \\ Marco Aurélio Marques Ferreira***** \\ Vasconcelos Reis Wakim******
}

Sumário: 1. Introdução; 2. Referencial teórico; 3. Procedimento metodológico; 4. O modelo de apuração de custo por aluno; 5. Resultados e discussões; 6. Conclusões.

Summary: 1 . Introduction; 2 . Theoretical framework; 3 . Methodological procedure; 4. The student-based costing model; 5. Results and discussions; 6. Conclusions.

Palavras-chave: ensino superior; custo por aluno; universidade pública.

KEY Words: undergraduate education; cost by student; public university.

\footnotetext{
* Artigo recebido em abr. 2008 e aceito em nov. 2009.

$\because *$ Mestre em Administração pela Universidade Federal de Viçosa. Professora assistente da Universidade Federal dos Vales do Jequitinhonha e Mucuri (UFVJM). Endereço: Rua do Cruzeiro, 1 — Jardim São Paulo — CEP 39801-000, Teófilo Otoni, MG, Brasil. E-mail: elicco2000@yahoo. com.br.

$* * *$ Doutora em economia aplicada. Professora adjunta da Universidade Federal de Viçosa (UFV). Endereço: Rua Olívia de Castro Almeida, 295/101 — Bairro Clélia Bernardes — CEP 36570-000, Viçosa, MG, Brasil. E-mail: sramos@ufv.br.

***** Doutor em administração. Professor adjunto da Universidade Federal de Viçosa (UFV). Endereço: Av. Peter Henry Rolfs, s/n — Departamento de Administração - Campus Universitário —CEP 36570-000, Viçosa, MG, Brasil. E-mail: abrantes@ufv.br.

$* * * * *$ Doutor em economia aplicada. Professor adjunto da Universidade Federal de Viçosa (UFV). Endereço: Av. Peter Henry Rolfs, s/n — Departamento de Administração — Campus Universitário — CEP 36570-000, Viçosa, MG, Brasil. E-mail: marcoaurelio@ufv.br.

******* Mestrando em desenvolvimento regional pela Universidade Federal do Tocantins. Professor auxiliar da Universidade Federal dos Vales do Jequitinhonha e Mucuri (UFVJM). Endereço: Rua do Cruzeiro, 1 - Jardim São Paulo - CEP 39801-000, Teófilo Otoni, MG, Brasil. E-mail: vasconceloswakim@yahoo.com.br.
} 
Apesar de a educação ser fator-chave no desenvolvimento social e econômico do país, os recursos públicos aplicados para tal fim são escassos para atender à demanda da sociedade. Esta, responsável por parte de seu provimento, também tem o direito de exigir eficiência na aplicação dos recursos. Este artigo apura o custo por aluno no ensino de graduação da Universidade Federal de Viçosa (UFV). Os dados foram obtidos por meio da análise de documentos, relatórios contábeis e relatórios gerados pela central de processamento de dados da instituição. O custo médio por aluno, apurado para o ano de 2004, foi de $\mathrm{R} \$ 8.965,91$. O custo por aluno dos departamentos variou de $\mathrm{R} \$$ 3.948,59 (curso de matemática) a $\mathrm{R} \$ 17.022,79$ (curso de zootecnia). As variáveis que mais influenciaram o custo por aluno foram os números de matrículas, de bens móveis, de docentes e de servidores técnico-administrativos. A mensuração de custo por aluno da UFV fornece orientação quanto ao modo de a instituição se expandir sem se onerar, bem como a melhor forma de aproveitar sua estrutura física.

The cost of undergraduate education in federal institutions: the case of the Federal University of Viçosa

Although education is a key factor in Brazil's social and economic development. public funding is not enough to answer society's demands. Partially responsible for this funding, society also has the right to demand efficiency in the application of funds. This article assesses the cost by undergraduate student at the Federal University of Viçosa (UFV). The data was obtained through the analysis of documents, accounting reports and reports generated by the institution's data center. The mean cost by student in 2004 was $R \$ 8,965.91$. The cost by student of the departments ranged from $\mathrm{R} \$ 3,948.59$ (Mathematics) to $\mathrm{R} \$ 17,022.79$ (Zootechnics). The most influential variables were the number of enrolments, assets, faculty members and technical-administrative personnel. Student-based costing can guide UFV's expansion without increasing costs, as well as the use of its installations.

\section{Introdução}

As universidades, principalmente as do setor público, exercem papel fundamental para o desenvolvimento econômico e social do país, entretanto os recursos públicos distribuídos entre as universidades públicas brasileiras estão diminuindo. Segundo dados da Associação Nacional de Dirigentes das Instituições Federais de Ensino Superior (Andifes), no período de 1995 a 2001, as instituições de ensino superior públicas perderam $24 \%$ dos recursos para custeio e $77 \%$ de recursos para investimento em infraestrutura.

Mesmo com esse quadro de redução de recursos financeiros, o governo federal e o Ministério da Educação (MEC) têm adotado uma postura de incentivo à expansão das instituições federais de ensino superior (Ifes). Desde 2003, têm sido feitos investimentos para melhorar as condições das Ifes, bem como estão sendo investidos recursos para a criação de novas instituições, visando alavancar a produção do conhecimento em diversas regiões do país. 
A atual matriz de alocação de recursos orçamentários das Ifes, adotada pela Secretaria de Educação Superior do MEC, utiliza diversos indicadores calculados de acordo com dados anuais, de caráter acadêmico, sendo que um dos principais indicadores é o aluno equivalente. Ao se contemplar o número de alunos para alocação de recursos, passa-se a fornecer um estímulo à expansão das vagas nas universidades federais.

Considerando a necessidade de crescimento das universidades e que os recursos públicos são insuficientes para atender a demanda da sociedade, torna-se evidente a importância da gestão de custos no setor público. As informações referentes aos custos podem servir como base para o estabelecimento de padrões, orçamentos e formas de previsão para os gastos das instituições, e também para acompanhar se o realizado está de acordo com valores preestabelecidos. Assim, o custo pode ter a função de contribuir para o autoconhecimento da instituição e para o estabelecimento de padrões de comparação com outras instituições públicas.

Nesse sentido, a mensuração do custo do setor público, especificamente da educação pública superior, constitui fator-chave para os gestores das Ifes, para os governantes e políticos e para a sociedade em geral. Portanto, conhecer o custo por aluno, nos cursos oferecidos por uma universidade, é de grande importância, pois informa o gasto de cada órgão da instituição em relação ao orçamento, bem como os cursos com possibilidade de expansão, sem acarretar gastos excessivos para a instituição.

Diante disso, este artigo apura o custo por aluno do ensino de graduação em uma instituição federal de ensino superior, especificamente a Universidade Federal de Viçosa, no ano de 2004, de modo a determinar as variáveis que compõem o custo do ensino, bem como identificar as que explicam esse custo. $\mathrm{O}$ artigo está dividido em seis partes. Após a introdução, apresentam-se o referencial teórico e o procedimento metodológico. Na seção 4, descreve-se a forma pela qual foi apurado o custo por aluno da instituição objeto de estudo. Na seção 5, são apresentados e discutidos os principais resultados e na última seção são apresentadas as conclusões.

\section{Referencial teórico}

\section{Custos em instituições federais de ensino superior}

No Brasil, as instituições de ensino superior são encontradas na forma de universidades, centros universitários, institutos de ensino e instituições isoladas. Essas instituições são formadas para oferecer benefícios de natureza social, 
cultural, educativa, econômica e tecnológica à sociedade. Portanto, somente tem sentido a existência de instituições de ensino, quer públicas, quer particulares, quando elas estão contribuindo para o desenvolvimento da nação.

As instituições de ensino superior, especialmente as universidades federais são complexas e apresentam enorme diversidade quanto às atividades que desenvolvem. Entretanto, todas contemplam basicamente as mesmas atividades-fim, isto é, ensino, pesquisa e extensão, sendo que algumas instituições podem dar maior ou menor ênfase em cada uma dessas atividades. Ratificando tal pensamento, Rosa (2004) afirma que a universidade pública brasileira pode ser considerada uma das instituições mais complexas da sociedade, em razão da sua peculiaridade. Essas instituições, em função do seu caráter público, estão submetidas às normas burocráticas e legais que regem a administração pública em geral.

Segundo Amaral (2005), a heterogeneidade entre as instituições é grande, sendo necessário dar um tratamento especial a essa questão. A diferença entre as instituições reflete-se em suas atividades, que dependem basicamente do número de mestres e doutores em cada uma delas. Há algumas instituições que, de acordo com o estágio em que se encontram, concentram-se mais na atividade de ensino. Existem também instituições em que o quadro de pessoal é altamente titulado e outras que ainda estão promovendo a qualificação de seus professores.

Como afirma Rosa (2004), as universidades públicas são instituições com características e realidades distintas das instituições privadas. A gestão dessas instituições identifica-se pela origem orçamentária de recursos públicos e pela rigidez da estrutura administrativa e organizacional. Pelo fato de utilizarem recursos públicos, estão subordinadas às leis dos órgãos públicos e às normas estabelecidas pelos tribunais de contas. A autonomia administrativa de seus gestores é muito restrita, dificultando, de certo modo, as ações relacionadas à racionalização dos recursos públicos.

O referido autor comenta que, no Brasil, os governos mantenedores das universidades públicas têm realizado cortes orçamentários com frequência, dificultando o desenvolvimento de suas atividades e, assim, impondo às instituições a busca por outras fontes e formas de financiamentos, para viabilizar o conjunto de suas atividades. Por essa razão, a sociedade em geral, especialmente a comunidade acadêmica, tem reivindicado maior transparência dos gastos públicos, no que se refere aos padrões de eficiência e eficácia.

De acordo com Silva, Morgan e Costa (2004), a determinação de custos em uma instituição de ensino, por meio da contabilidade de custos, é complexa, pois é necessário que os custos sejam alocados. Isso ocorre porque muitas 
unidades das universidades, tanto acadêmicas quanto administrativas e de prestação de serviço possuem custos comuns, ou seja, são unidades com multiprodutos, formadas a partir de insumos comuns.

A contabilidade de custos é conceituada por Leone (2001) como um ramo da contabilidade financeira e consiste em reunir, organizar, analisar e interpretar os custos dos produtos ou serviços de uma organização para controlar e auxiliar o gestor na tomada de decisão e no planejamento das atividades. Assim, Maher (2001) afirma que a contabilidade de custos tem como função mensurar, registrar e relatar as informações referentes a custos. O termo custos é definido por Crepaldi (2002) como gasto referente à transformação de ativos, ou seja, relativo à atividade de produção.

As universidades públicas são consideradas, em diversos estudos, organizações de múltiplos produtos, destacando como principais: o ensino, a pesquisa e a extensão (Morgan, 2004; Koshal e Koshal, 1999; Silva, Morgan e Costa, 2004). Segundo Koshal e Koshal (1999), o fato de existir entre as instituições diferentes objetivos faz com que as variáveis consideradas na apuração do custo também sejam distintas.

$\mathrm{Na}$ apuração do custo, pressupõe-se a definição de um objeto de custo. O objeto de custo é "qualquer coisa para a qual se deseja uma mensuração de custos. Pode ser um produto, uma máquina, um serviço ou um processo" (Horngren, Foster e Datar, 2000:19). Nesse sentido, Hansen e Mowen (2003) definem o objeto de custo como qualquer item - produtos, serviços e departamentos - em que os custos podem ser mensurados e atribuídos. No caso das instituições de ensino superior, o custo do ensino pode ser considerado um tipo de objeto de custo.

Na educação superior, segundo Morgan (2004), pode ser observado o custo para o indivíduo, que consiste no sacrifício de recursos que o aluno tem para frequentar a universidade, como a aquisição de livros, materiais de laboratório, fotocópias, taxas e mensalidades, nos casos das universidades particulares. Além do custo para o indivíduo, tem-se o custo da instituição, que representa o sacrifício da sociedade para fornecer a educação superior. Portanto, o sacrifício total para obtenção da educação superior é determinado pela soma do custo para o indivíduo e o da instituição.

No Brasil, o custo por aluno do ensino superior foi comparado àquele referente aos alunos dos outros níveis de ensino. Na concepção de Amaral (2005), quando se faz esse tipo de comparação não se pode esquecer que o ensino superior, em função de sua indissociabilidade entre ensino, pesquisa e extensão, é mais dispendioso que os outros níveis de ensino. Assim, gera-se um dilema em relação aos gastos com o ensino superior, quando se calcula a quantia aplicada, por aluno, nos vários níveis de ensino do país. 
Na visão do referido autor, a realização de comparações internacionais é bastante difícil, pois, em alguns países, as instituições de ensino superior são responsáveis pela manutenção de hospitais universitários que prestam serviço à população carente, bem como mantêm bibliotecas comunitárias, possuem escolas de ensino fundamental e ensino médio e, em seus orçamentos, encontram-se os pagamentos de aposentadoria e precatórios. Em outros países, entretanto, essas despesas não estão presentes. Assim, os custos são comparáveis, somente, com a introdução de adaptações que produzam compatibilidade de suas atividades e de seus gastos.

Outros autores corroboram a ideia de Amaral (2005) ao afirmarem que

a situação parece ser ainda mais complicada quando se pretende fazer comparações entre instituições, pois a maioria dos sistemas não apresenta padronização mínima necessária para possíveis confrontações. Enquanto alguns pontos são considerados relevantes por um determinado autor ou em uma determinada proposta, não o são por outro e, mais do que isso, algumas vezes esses fatores sequer são mencionados. Parece não existir um argumento forte o suficiente que supere as limitações que podem ser observadas nos métodos propostos. Consequentemente, ainda não se consegue encontrar uma proposta que seja considerada e adotada pela maioria das instituições.

(Reinert e Reinert, 2005:5)

Morgan (2004), baseando-se em estudo realizado na Universidade de Brasília sobre custo por aluno, concluiu que a apuração de custo pode fornecer informação sobre os recursos gastos em determinado órgão das universidades, o que auxilia nas decisões sobre a utilização da capacidade disponível e na aplicação de ações racionais para propiciar maior eficiência na alocação dos recursos. Além disso, pode ser uma variável no cálculo do retorno dos investimentos públicos, realizados nessas instituições.

Um sistema de custos, adequado às particularidades das universidades federais, é fundamental, servindo como fonte de informações gerenciais, visando à melhoria da eficácia e permitindo uma gestão efetivamente autônoma (Peter e colaboradores, 2003). Portanto, sem medida de custos, fica difícil medir a eficiência, uma vez que ela é obtida por meio da relação entre o resultado alcançado e o recurso consumido para obtê-lo.

A definição sobre os componentes do custo de ensino e a maneira de determiná-los é relevante para a sociedade que deseja saber se os recursos aplicados nas universidades estão lhe trazendo algum benefício, assim como para a própria instituição, que deseja melhorar a eficiência na utilização dos seus 
recursos. Além disso, as informações sobre os custos são ferramentas que contribuem para o controle e para a tomada de decisão nas instituições, constituindose, também, em fonte de informação para a elaboração do orçamento.

\section{Alguns aspectos da apuração do custo das Ifes}

Cada Ifes possui uma realidade regional e local, o que faz com que essas instituições apresentem características diferentes. Além disso, apesar de desenvolverem as mesmas atividades, as universidades federais possuem diferentes estruturas organizacionais. As variações aparecem nos órgãos de assessoria, no número de unidades acadêmicas e em nomenclaturas. No entanto, todas as universidades possuem, em sua estrutura, reitoria, vice-reitoria, conselhos superiores, assessorias, pró-reitorias e unidades acadêmicas em que se localizam os departamentos acadêmicos, coordenações de cursos de graduação e pósgraduação, programas de extensão e centro de pesquisas (Peter et al., 2003).

Existem também variações quanto aos recursos financeiros destinados a cada instituição federal de ensino superior. Esses recursos são oriundos da arrecadação de tributos, sendo, basicamente, recursos provenientes do Tesouro. Além dessa fonte de recurso, há um percentual menor captado por outras fontes, além da arrecadação própria das Ifes.

Do montante dos custos das universidades federais brasileiras, a quantia mais significativa está concentrada em pessoal e encargos sociais. Estudos mostram que, nas universidades, o custo com salários varia de $80 \%$ a $90 \%$ (Morgan, 2004; Peter e colaboradores, 2003). Para Peter e colaboradores (2003), tais custos são denominados como custos fixos no curto prazo, representando cerca de $80 \%$ dos custos totais.

O estudo realizado por Peter e colaboradores (2003) na Universidade Federal do Ceará, tendo como base os dados do exercício de 2000, mostrou que os custos com pessoal e encargos sociais representavam cerca de $93 \%$ do custo total da instituição. Assim, a preocupação maior de um sistema de custos a ser implantado deve estar concentrada no tratamento dos custos fixos, justamente por constituírem a parcela mais significativa dos custos nas universidades federais.

Segundo Reinert e Reinert (2005), uma forma de reduzir os custos fixos é garantir a ocupação máxima da capacidade da instituição e não reduzir os números na folha de pagamento. Assim, se uma universidade federal tem capacidade para atender determinado número de estudantes, quanto mais próximo deste for o número de matrículas, menores serão os custos unitários. 
De acordo com os referidos autores, em razão de sua complexidade, as Ifes apresentam os mais variados custos (por estudante, do ensino, da pesquisa, da extensão). Entre os citados, o mais discutido é o custo por estudante. Na maioria das vezes, o custo por estudante é apurado, tendo como indicador do custo total somente o orçamento do Tesouro. Entretanto, além de receber recursos do Tesouro, as universidades captam recursos de outras fontes e, também, possuem recursos próprios.

No entanto, Gaetani e Schwartzman (1991), citados por Reinert e Reinert (2005), comentam que a solução estaria na organização de um orçamento de ensino que englobaria todas as despesas correntes, após excluídas as destinadas à pesquisa e extensão, restaurantes, moradias estudantis e hospitais universitários.

Segundo Peter e colaboradores (2003), na apuração do custo do ensino deveriam ser considerados apenas os gastos realizados com recursos provenientes do orçamento da instituição. Os recursos originários de outras fontes não deveriam ser incluídos no cálculo, visto que não existe registro de seu consumo. Além do mais, em razão desses recursos não serem relevantes, uma preocupação com esse aspecto implicaria o comprometimento da relação custo-benefício do modelo sugerido.

Na determinação do custo por aluno, os custos relacionados a aposentadorias e pensões do pessoal inativo, como afirmam Amaral (2005), Morgan (2004) e Peter e colaboradores (2003), não devem ser considerados no cálculo, pois, referem-se a compromissos que não têm nenhuma tradução, em termos de produtos e serviços, no presente. Da mesma forma, a parcela referente aos precatórios deve ser excluída do cálculo.

As preocupações com o gerenciamento de custos nas universidades federais são apropriadas e cada vez maiores. Contudo, os sistemas de apuração de custos desenvolvidos até o momento parecem não atender às necessidades das próprias instituições, do governo e da sociedade em geral.

\section{Procedimento metodológico}

A pesquisa desenvolvida tem natureza exploratória e bibliográfica. Conforme Vergara (2005), a pesquisa exploratória pretende atingir uma área, na qual há pouco conhecimento acumulado, permitindo aumentar o conhecimento sobre o fenômeno que deseja investigar e esclarecer os principais conceitos. A pesquisa bibliográfica, segundo a referida autora, é de grande utilidade para se conhecer as contribuições científicas do passado sobre determinado fenômeno. 
A investigação foi também documental, pois foram utilizados documentos internos à UFV, que tratam do objeto de estudo. De acordo com Vergara (2005:48), "a investigação documental é realizada em documentos conservados em órgãos públicos e privados de qualquer natureza".

Este artigo nasceu de um estudo de caso em que a unidade de análise é a Universidade Federal de Viçosa (UFV). Conforme Gil (1996), o estudo de caso tem maior utilidade nos estudos exploratórios. Yin (2001) acrescenta que, através do estudo de caso, é possível investigar o fenômeno com maior profundidade, dentro do seu contexto e preservando as suas características significativas. Além disso, o autor considera o estudo de caso uma estratégia de pesquisa, na medida em que compreende uma lógica de planejamento adequada ao problema de pesquisa e às suas circunstâncias, possibilitando a incorporação de abordagens específicas tanto na coleta quanto na análise dos dados.

A UFV é uma organização com múltiplos produtos, visto que possui como principais atividades o ensino, a pesquisa e a extensão. Tem uma estrutura acadêmica com 38 cursos de graduação, 30 programas de pós-graduação stricto sensu, 20 de mestrado e doutorado e 10 no mestrado, além de 14 cursos de especialização, distribuídos por várias áreas do conhecimento. Além disso, conta com 9.838 alunos de graduação, 1.706 alunos dos programas de pós-graduação stricto sensu, sendo 991 de mestrado e 715 de doutorado. São 779 professores de ensino superior, dos quais, 22\% têm mestrado e $70 \%$ doutorado. Também compõem esse quadro 2.511 funcionários técnico-administrativos (UFV, 2005).

O cálculo do custo do ensino de graduação da UFV foi realizado tendo como base o ano de 2004. Os dados foram coletados junto ao estatuto da instituição; balancete contábil, discriminado por rubrica orçamentária; e relatório gerado pelo sistema da central de processamento de dados (CPD).

No intuito de verificar as variáveis que influenciaram o comportamento do custo por aluno, identificou-se, com base na teoria e na realidade da instituição estudada, as principais variáveis: número total de funcionários (docentes e técnico-administrativos) dos departamentos, número de alunos de graduação, número de matrículas nos cursos da graduação, bens móveis (equipamentos), área útil e carga horária das atividades de ensino de graduação.

A fim de verificar a distribuição dos dados das variáveis, consideradas na apuração do custo por aluno, utilizou-se a análise estatística descritiva, apurando-se a média, desvio padrão, valores máximo e mínimo, curtose, assimetria e coeficiente de variação. Além disso, gerou-se modelo de regressão 
linear múltipla por meio do método dos mínimos quadrados. Nesse caso, utilizou-se o programa Statistical Package for Social Sciences (SPSS), versão 15.0, para selecionar as variáveis que melhor explicam o resultado encontrado para o custo por aluno do ensino de graduação da UFV.

\section{0 modelo de apuração de custo por aluno}

Para o cálculo do custo por aluno, inicialmente a estrutura da instituição foi dividida em: órgãos administrativos, essenciais ao funcionamento da instituição, mas não exercem atividade de ensino de graduação e pós-graduação; e órgãos acadêmicos, constituindo os próprios departamentos de ensino, que desenvolvem as atividades de ensino, pesquisa e extensão.

A primeira depuração foi identificar os recursos repassados pelo Tesouro, já que a opção foi trabalhar apenas com essa fonte de recurso. Além disso, foram consideradas somente as despesas correntes. Entre elas, identificou-se como custo dos órgãos administrativos e acadêmicos, material de consumo; diárias - pessoal civil; despesa com locomoção; auxílio transporte e alimentação; pessoal docente e técnico-administrativo ativo; estagiário; telefone; energia elétrica e outras despesas correntes. Ressalta-se que os itens vinculados à despesa de capital, às aposentadorias, reformas, sentenças judiciais e pensões foram eliminados do cálculo.

O tratamento dos custos obedeceu à sistemática do custeio por absorção e o regime contábil de competência. Esse método possibilitou o controle dos custos, permitindo sua apropriação por unidades (centros de custos). Os órgãos acadêmicos e administrativos, identificados na estrutura organizacional da UFV, constituem os centros de custos deste artigo.

Assim, os recursos orçamentários diretos foram relacionados aos órgãos tanto administrativos quanto acadêmicos. Os custos identificados nos órgãos administrativos, que estão relacionados direta e indiretamente com o ensino, foram distribuídos entre os departamentos de acordo com critérios aplicáveis para cada caso, sendo que a principal base utilizada foi o número de alunos matriculados. A apropriação dos custos fixos e variáveis dos órgãos administrativos aos órgãos acadêmicos foi realizada em conjunto, utilizando o método da taxa única. Segundo Horngren, Foster e Datar (2000), o método da taxa única não separa custos fixos de custos variáveis. Tal método utiliza uma única taxa, para apropriar todos os custos ao objeto de custo. 
Os departamentos de ensino possuem, além desta, as atividades de pesquisa e extensão. Na apuração do custo dos departamentos não se fez distinção entre os custos relacionados às três atividades, pois são atividades essenciais à formação do aluno de graduação, nos padrões qualitativos estabelecidos pela instituição analisada - a tríade indissociável ensino, pesquisa e extensão.

Nesse caso, o custo de cada unidade de ensino foi composto pelo custo diretamente identificado e pelo custo apropriado dos órgãos administrativos ao ensino de graduação dos departamentos, conforme a fórmula 1 :

$$
C E G_{A}=C_{D} \times\left(\frac{N M_{C R}}{N M_{G R}+N M_{P G}}\right)+\sum C D_{G R}
$$

em que

$C E G_{A}=$ custo do ensino de graduação antes da distribuição entre departamentos; $C_{D}=$ custo diretamente identificado em cada departamento; $N M_{G R}=$ número de matrículas dos alunos de graduação, por departamento; $N M_{P G}=$ número de matrículas dos alunos da pós-graduação; $C D_{G R}=$ custo distribuído ao ensino de graduação, por departamento.

Os departamentos de ensino da UFV, além de serem responsáveis pelos cursos que abrigam, colaboram com cursos oferecidos por outros departamentos. Nesse caso, é permitido, aos alunos de determinado departamento, cursarem disciplinas ofertadas por diferentes departamentos. Portanto, os órgãos acadêmicos produzem ensino entre eles, uma vez que um contribui para a formação de aluno de outro.

Diante disso, uma alternativa para a distribuição de custo entre os departamentos foi o número de alunos de cada curso, que estão matriculados em disciplinas oferecidas por outros departamentos, conforme a fórmula 2.

$$
C E G_{D}=\sum_{i=1}^{n} N M D_{1, n} \times C M D_{n}
$$

em que

$C E G_{D}=$ custo do ensino de graduação depois da distribuição entre os departamentos;

$N M D=$ número de matrículas do departamento;

$C M D=$ custo por matrícula do departamento;

$n=$ número de departamentos. 
Após realizar a distribuição dos custos entre os departamentos, o montante do custo do ensino de graduação de cada departamento foi dividido pelo total anual de alunos de graduação. Assim, o custo por aluno de graduação foi obtido por meio da fórmula 3 .

$$
C A_{G R}=C E G_{D} / N_{G R}
$$

em que

$C A_{G R}=$ custo por aluno de graduação;

$N_{G R}=$ número anual de alunos de graduação.

Cabe ressaltar que, apesar de existirem metodologias que adotam o conceito de aluno equivalente na apuração do custo por aluno (Amaral, 2005; Brasil, 2005), esse denominador não foi utilizado pois, neste artigo, a apuração do custo por departamento de ensino envolveu apenas uma modalidade - ensino de graduação. Assim, empregou-se como denominador a soma do número de alunos de graduação, referente aos dois períodos (semestres acadêmicos) do ano de 2004.

Portanto, o modelo definido para apurar o custo por aluno dos cursos de graduação da UFV pode ser resumido em três etapas:

- etapa 1 - distribuição dos custos entre órgãos administrativos - nessa etapa os custos de alguns órgãos administrativos, relacionados indiretamente com o ensino de graduação, foram distribuídos aos órgãos subordinados;

v etapa 2 - distribuição dos custos dos órgãos administrativos para os órgãos acadêmicos - nessa etapa os custos identificados nos órgãos administrativos, que estão vinculados direta e indiretamente ao ensino de graduação, foram alocados aos departamentos de ensino, com base no critério mais apropriado a cada situação;

- etapa 3 - distribuição dos custos entre os departamentos acadêmicos - na terceira e última etapa, realizou-se a alocação dos custos entre os departamentos, de acordo com o número de alunos matriculados em disciplinas diferentes daquelas oferecidas pelo departamento de origem. 
Modelo de apuração do custo do ensino de graduação

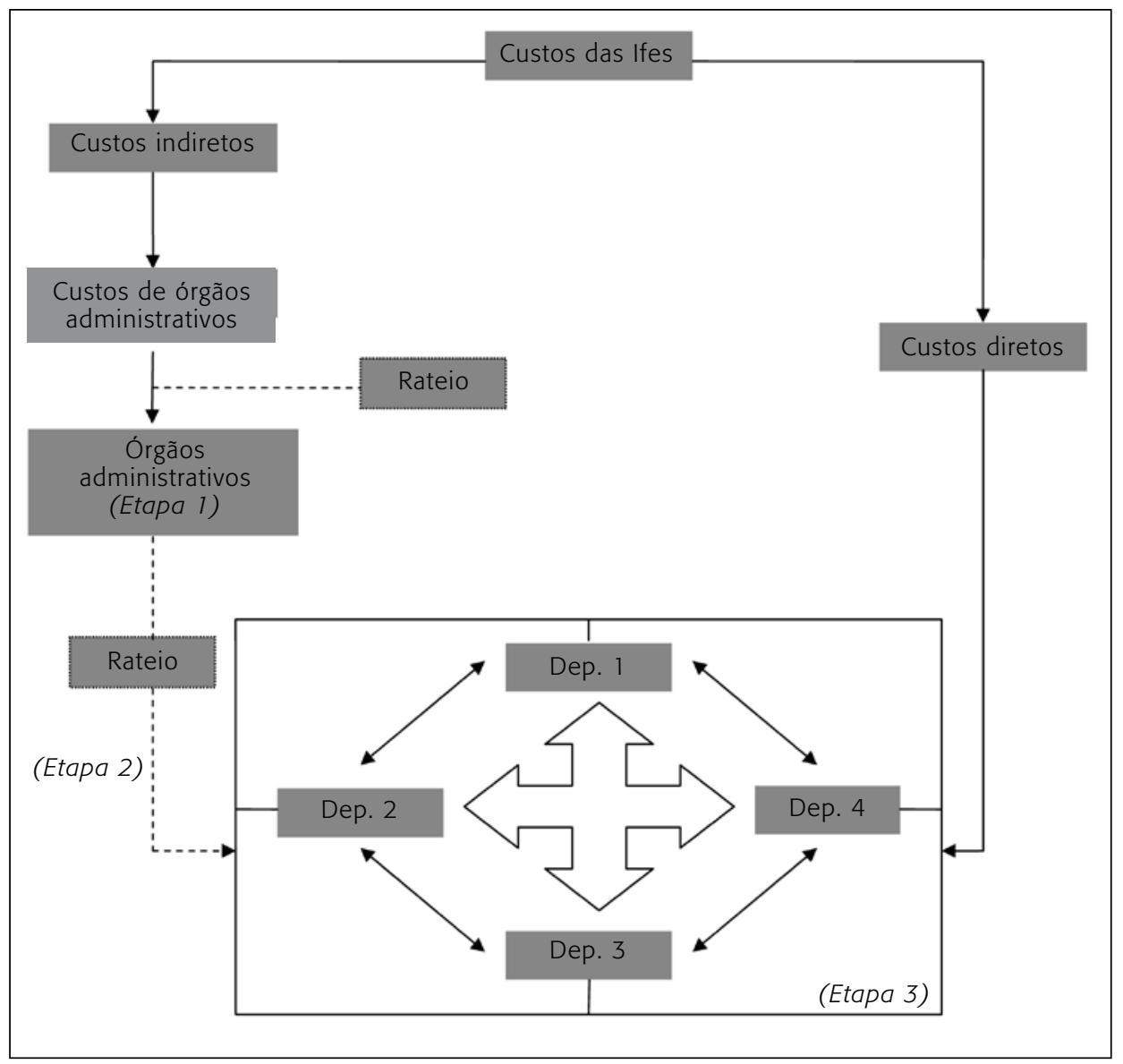

\section{Resultados e discussões}

Para cálculo do custo por aluno, o valor gasto pelos órgãos administrativos e acadêmicos totalizou $\mathrm{R} \$ 93.758 .877,16$, o que corresponde a 47,93\% do orçamento da UFV do ano de 2004 que foi de R\$ 195.597.912,70. Após a realização do rateio dos custos dos órgãos administrativos para os acadêmicos e a separação entre os custos da graduação e pós-graduação, o custo do ensino de graduação dos departamentos correspondeu a $\mathrm{R} \$ 76.434 .348,72$.

O custo total do ensino de graduação da UFV representa 39,08\% (que totalizam R\$76.434.348,72) do orçamento total, executado no ano de 2004. Ainda em relação ao custo total dos departamentos, o custo do ensino de gra- 
duação representa 52,90\% das despesas orçamentárias (excluindo o total de despesas com pessoal inativo e pensionistas e sentenças judiciais).

Do custo total apurado nos departamentos, para o ensino de graduação, $76,33 \%$ (R\$ 58.342.149,22) referem-se à parte dos custos identificados diretamente, o que representa $29,83 \%$ do orçamento total realizado em 2004. O restante dos custos ( $\mathrm{R} \$ 18.092 .199,50)$ desses órgãos está relacionado aos custos recebidos dos órgãos administrativos.

Na composição do custo total do ensino de graduação, $71,14 \%$ referemse ao custo de pessoal docente e técnico-administrativo dos departamentos, desconsiderando o gasto com pessoal dos órgãos administrativos. No entanto, o gasto de pessoal diretamente relacionado ao ensino de graduação (docentes) representa $57,43 \%$ do custo total do ensino de graduação.

A UFV possui 30 departamentos de ensino, distribuídos entre os quatro centros de ciências, conforme o quadro. Existem departamentos com mais de 50 anos, como os de Fitotecnia e Economia Doméstica, assim como departamentos novos, com pouco mais de dois anos, como os departamentos de Engenharia Elétrica e Produção e de Artes e Humanidades. Além disso, há departamentos que, embora não possuam cursos de graduação, oferecem disciplinas para os cursos de graduação de outros departamentos, como é o caso dos departamentos de Fitopatologia, Solos, Biologia Animal e Geral e Microbiologia. Tais departamentos tiveram seus custos alocados aos departamentos, para os quais oferecem disciplinas.

\section{Centros de ciências e respectivos departamentos de ensino}

\begin{tabular}{|l|}
\hline Centro de Ciências Agrárias (CCA) \\
\hline Departamento de Economia Rural (DER) \\
Departamento de Engenharia Agrícola (DEA) \\
Departamento de Engenharia Florestal (DEF) \\
Departamento de Fitopatologia (DFP) \\
Departamento de Fitotecnia (DFT) \\
Departamento de Solos (DPS) \\
Departamento de Zootecnia (DZO) \\
\hline Centro de Ciências Biológicas e da Saúde (CCB) \\
\hline Departamento de Biologia Animal (DBA) \\
Departamento de Biologia Geral (DBG) \\
Departamento de Biologia Vegetal (DBV) \\
Departamento de Bioquímica e Biologia Molecular (DBB) \\
\hline
\end{tabular}




\begin{tabular}{|l|}
\hline Departamento de Educação Física (DES) \\
Departamento de Microbiologia (DMB) \\
Departamento de Nutrição e Saúde (DNS) \\
Departamento de Veterinária (DVT) \\
\hline Centro de Ciências Exatas e Tecnológicas (CCE) \\
\hline Departamento de Arquitetura e Urbanismo (DAU) \\
Departamento de Engenharia Civil (DEC) \\
Departamento de Física (DPF) \\
Departamento de Informática (DPI) \\
Departamento de Matemática (DMA) \\
Departamento de Química (DEQ) \\
Departamento de Tecnologia de Alimentos (DTA) \\
Departamento de Engenharia Elétrica e de Produção (DEP) \\
\hline Centro de Ciências Humanas, Letras e Artes (CCH) \\
\hline Departamento de Administração (DAD) \\
Departamento de Direito (DPD) \\
Departamento de Economia (DEE) \\
Departamento de Economia Doméstica (DED) \\
Departamento de Educação (DPE) \\
\hline
\end{tabular}

Com base no custo apurado em cada departamento e no número de matrículas efetuadas no primeiro e segundo períodos de 2004, foi possível calcular o custo por matrícula, por departamento, antes da distribuição dos custos entre as unidades de ensino, conforme apresentado na tabela 1.

Tabela 1

Custo por matrícula do ensino de graduação em 2004, por departamento

\begin{tabular}{|ccccccc|}
\hline Dep. & $\begin{array}{c}\text { Custo sem } \\
\text { distribuição } \\
(\mathrm{R} \$)\end{array}$ & $\begin{array}{c}\text { № de } \\
\text { matrículas }^{\mathrm{a}}\end{array}$ & $\begin{array}{c}\text { Custo por } \\
\text { matrícula } \\
(\mathrm{R} \$)\end{array}$ & $\begin{array}{c}\text { Custo com } \\
\text { distribuição } \\
(\mathrm{R} \$)\end{array}$ & $\begin{array}{c}\text { № de } \\
\text { matrículas }^{\mathrm{b}}\end{array}$ & $\begin{array}{c}\text { Custo por } \\
\text { matrícula } \\
(\mathrm{R} \$)\end{array}$ \\
\cline { 2 - 7 } & $(\mathrm{A})$ & $(\mathrm{B})$ & $\mathrm{C}=(\mathrm{A} / \mathrm{B})$ & $(\mathrm{D})$ & $(\mathrm{E})$ & $\mathrm{F}=(\mathrm{D} / \mathrm{E})$ \\
\hline DER & $2.848 .047,98$ & 3.576 & 796,43 & $2.333 .078,70$ & 3.714 & 628,18 \\
DEA & $3.179 .927,25$ & 2.488 & $1.278,11$ & $2.402 .352,15$ & 2.490 & 964,80 \\
DEF & $3.896 .696,96$ & 2.742 & $1.421,11$ & $4.428 .727,75$ & 3.948 & $1.121,76$ \\
\hline
\end{tabular}

Continua 


\begin{tabular}{|c|c|c|c|c|c|c|}
\hline Dep. & $\begin{array}{l}\text { Custo sem } \\
\text { distribuição } \\
\text { (R\$) }\end{array}$ & $\begin{array}{c}\text { № de } \\
\text { matrículas }\end{array}$ & $\begin{array}{c}\text { Custo por } \\
\text { matrícula } \\
(\mathrm{R} \$)\end{array}$ & $\begin{array}{l}\text { Custo com } \\
\text { distribuição } \\
\text { (R\$) }\end{array}$ & $\begin{array}{c}\text { № de } \\
\text { matrículas }\end{array}$ & $\begin{array}{l}\text { Custo por } \\
\text { matrícula } \\
(\mathrm{R} \$)\end{array}$ \\
\hline & (A) & (B) & $C=(A / B)$ & (D) & (E) & $F=(D / E)$ \\
\hline DFP & $1.527 .125,26$ & 546 & $2.796,93$ & 0 & 0 & 0 \\
\hline DFT & $5.718 .918,96$ & 3.019 & $1.894,31$ & $16.008 .015,88$ & 13.174 & $1.215,12$ \\
\hline DPS & $2.347 .140,42$ & 1.972 & $1.190,23$ & 0 & 0 & 0 \\
\hline DZO & $4.488 .477,32$ & 1.993 & $2.252,12$ & $5.208 .972,53$ & 3.771 & $1.381,32$ \\
\hline DBA & $2.963 .755,25$ & 1.954 & $1.516,76$ & 0 & 0 & 0 \\
\hline DBG & $2.682 .509,69$ & 3.633 & 738,37 & 0 & 0 & 0 \\
\hline DBV & $1.771 .291,09$ & 1.199 & $1.477,31$ & $2.318 .685,32$ & 2.507 & 924,88 \\
\hline DBB & $1.654 .413,04$ & 2.432 & 680,27 & 1.220.677,47 & 1.723 & 708,46 \\
\hline DES & $2.718 .836,17$ & 3.148 & 863,67 & $3.346 .430,73$ & 3.964 & 844,21 \\
\hline DMB & $1.256 .540,99$ & 1.277 & 983,98 & 0 & 0 & 0 \\
\hline DNS & $2.340 .234,20$ & 2.278 & $1.027,32$ & $2.719 .262,81$ & 2.813 & 966,68 \\
\hline DVT & $3.249 .354,18$ & 2.287 & $1.420,79$ & $4.327 .780,12$ & 3.315 & $1.305,51$ \\
\hline DAU & $1.767 .443,58$ & 2.397 & 737,36 & $1.525 .992,75$ & 1.992 & 766,06 \\
\hline DEC & $3.245 .655,71$ & 3.575 & 907,88 & $5.966 .972,02$ & 7.736 & 771,33 \\
\hline DPF & $2.296 .933,14$ & 4.202 & 546,63 & $489.108,18$ & 944 & 518,12 \\
\hline DPI & $2.409 .561,03$ & 4.247 & 567,36 & $924.489,59$ & 1.753 & 527,38 \\
\hline DMA & $2.283 .641,13$ & 5.860 & 389,70 & $481.728,01$ & 1.024 & 470,44 \\
\hline DEQ & $2.747 .459,73$ & 4.778 & 575,02 & $1.156 .884,30$ & 2.006 & 576,71 \\
\hline DTA & $3.191 .542,13$ & 2.868 & $1.112,81$ & $4.201 .829,36$ & 5.025 & 836,18 \\
\hline DEP & $1.030 .869,81$ & 910 & $1.132,82$ & $2.591 .877,06$ & 3.510 & 738,43 \\
\hline DAD & $2.250 .332,47$ & 4.563 & 493,17 & $2.247 .434,94$ & 4.477 & 502,00 \\
\hline DPD & $1.607 .775,90$ & 4.171 & 385,47 & $1.481 .416,86$ & 3.650 & 405,87 \\
\hline DEE & $2.095 .011,36$ & 4.320 & 484,96 & $1.216 .774,66$ & 2.527 & 481,51 \\
\hline DED & $2.107 .622,75$ & 1.438 & $1.465,66$ & $3.175 .918,18$ & 2.948 & $1.077,31$ \\
\hline DPE & $2.899 .233,34$ & 5.854 & 495,26 & $1.545 .450,33$ & 3.040 & 508,37 \\
\hline DLA & $1.956 .561,98$ & 3.569 & 548,21 & $1.503 .346,01$ & 2.783 & 540,19 \\
\hline DAH & $1.901 .435,90$ & 4.076 & 466,50 & $3.611 .143,00$ & 6.538 & 552,33 \\
\hline Total & $76.434 .348,72$ & 91.372 & 836,52 & $76.434 .348,72$ & 91.372 & 836,52 \\
\hline
\end{tabular}

Obs.: a número de matrículas em disciplinas oferecidas pelo departamento ao qual o curso do aluno está vinculado; ${ }^{b}$ número de matrículas em disciplinas oferecidas pelo próprio departamento e por departamento diferente daquele que oferece o curso em que o aluno está matriculado. 
Nota-se que o custo total médio dos alunos de graduação matriculados nas disciplinas oferecidas pelos departamentos foi de $R \$ 836,52$, sendo que o Departamento de Fitopatologia apresentou maior valor por matrícula ( $R$ \$ 2.796,93), em função de ter apresentado número reduzido de matrículas, uma vez que não possui curso de graduação e está mais voltado para a pósgraduação. Os departamentos de Zootecnia $(\mathrm{R} \$ 2.252,12)$ e Fitotecnia ( $\mathrm{R} \$$ $1.894,31$ ) também apresentaram elevado custo por matrícula, por possuírem elevado número de funcionários. O Departamento de Direito obteve menor valor por matrícula ( $\mathrm{R} \$ 385,47)$, pois trata-se de um departamento da UFV que apresenta baixa quantidade de funcionários (docentes e servidores técnico-administrativos).

Realizada a distribuição dos custos entre os departamentos, apurou-se o custo médio das matrículas dos alunos de determinado departamento. Nesse caso, consideram-se as matrículas em disciplinas do departamento ao qual o curso está vinculado e matrículas em disciplinas oferecidas por outros departamentos. Esse resultado pode ser observado na tabela 1. Nota-se que o custo médio por matrícula variou de $\mathrm{R} \$ 405,87$ a $\mathrm{R} \$ 1.381,32$. O departamento que apresentou maior custo médio, por matrícula, foi o de Zootecnia, e o de menor custo foi o de Direito. Os alunos do Departamento de Zootecnia, além de se matricularem em disciplinas do próprio departamento, que tem elevado custo por matrícula, realizam disciplinas em departamentos cujo custo por matrícula é alto, como Veterinária, Fitotecnia, Biologia Vegetal, Engenharia Agrícola e outros. Os alunos do Departamento de Direito, entretanto, cursam aproximadamente $85 \%$ das disciplinas no próprio departamento, que apresentou menor custo por matrícula.

A tabela 2 apresenta o custo médio de cada departamento, incorrido em 2004, para oferecer suas disciplinas.

Tabela 2

Custo total médio por disciplina do ensino de graduação em 2004

\begin{tabular}{|cccccc|}
\hline Dep. & $\begin{array}{c}\text { Disciplinas } \\
\text { oferecidas }\end{array}$ & Matrículas & $\begin{array}{c}\text { Média de } \\
\text { alunos } \\
\text { por disciplina }\end{array}$ & $\begin{array}{c}\text { Custo por matrícula } \\
(\mathrm{R} \$)\end{array}$ & $\begin{array}{c}\text { Custo médio por } \\
\text { disciplina } \\
\text { (R\$) }\end{array}$ \\
\cline { 2 - 6 } & $(\mathrm{A})$ & $(\mathrm{B})$ & $\mathrm{C}=(\mathrm{B} / \mathrm{A})$ & $\mathrm{D}$ & $\mathrm{E}=(\mathrm{C} \times \mathrm{D})$ \\
\hline DER & 66 & 3.576 & 54 & 796,43 & $43.152,24$ \\
DEA & 54 & 2.488 & 46 & $1.278,11$ & $58.887,54$ \\
DEF & 94 & 2.742 & 29 & $1.421,11$ & $41.454,22$ \\
DFP & 13 & 546 & 42 & $2.796,93$ & $117.471,17$ \\
\hline
\end{tabular}

Continua 


\begin{tabular}{|c|c|c|c|c|c|}
\hline Dep. & $\begin{array}{l}\text { Disciplinas } \\
\text { oferecidas }\end{array}$ & Matrículas & $\begin{array}{c}\text { Média de } \\
\text { alunos } \\
\text { por disciplina }\end{array}$ & $\begin{array}{c}\text { Custo por matrícula } \\
\text { (R\$) }\end{array}$ & $\begin{array}{l}\text { Custo médio por } \\
\text { disciplina } \\
(\mathrm{R} \$)\end{array}$ \\
\hline & (A) & (B) & $C=(B / A)$ & D & $E=(C \times D)$ \\
\hline DFT & 55 & 3.019 & 55 & $1.894,31$ & $103.980,34$ \\
\hline DPS & 22 & 1.972 & 90 & $1.190,23$ & $106.688,20$ \\
\hline DZO & 83 & 1.993 & 24 & $2.252,12$ & $54.078,04$ \\
\hline DBA & 40 & 1.954 & 49 & $1.516,76$ & $74.093,88$ \\
\hline DBG & 42 & 3.633 & 87 & 738,37 & $63.869,28$ \\
\hline DBV & 21 & 1.199 & 57 & $1.477,31$ & $84.347,19$ \\
\hline DBB & 25 & 2.432 & 97 & 680,27 & $66.176,52$ \\
\hline DES & 76 & 3.148 & 41 & 863,67 & $35.774,16$ \\
\hline DMB & 15 & 1.277 & 85 & 983,98 & $83.769,40$ \\
\hline DNS & 63 & 2.278 & 36 & $1.027,32$ & $37.146,57$ \\
\hline DVT & 45 & 2.287 & 51 & $1.420,79$ & $72.207,87$ \\
\hline DAU & 48 & 2.397 & 50 & 737,36 & $36.821,74$ \\
\hline DEC & 104 & 3.575 & 34 & 907,88 & $31.208,23$ \\
\hline DPF & 52 & 4.202 & 81 & 546,63 & $44.171,79$ \\
\hline DPI & 48 & 4.247 & 88 & 567,36 & $50.199,19$ \\
\hline DMA & 47 & 5.860 & 125 & 389,70 & $48.588,11$ \\
\hline DEQ & 50 & 4.778 & 96 & 575,02 & $54.949,19$ \\
\hline DTA & 73 & 2.868 & 39 & $1.112,81$ & $43.719,76$ \\
\hline DEP & 38 & 910 & 24 & $1.132,82$ & $27.128,15$ \\
\hline DAD & 51 & 4.563 & 89 & 493,17 & $44.124,17$ \\
\hline DPD & 65 & 4.171 & 64 & 385,47 & $24.735,01$ \\
\hline DEE & 50 & 4.320 & 86 & 484,96 & $41.900,23$ \\
\hline DED & 55 & 1.438 & 26 & $1.465,66$ & $38.320,41$ \\
\hline DPE & 86 & 5.854 & 68 & 495,26 & $33.712,02$ \\
\hline DLA & 102 & 3.569 & 35 & 548,21 & $19.181,98$ \\
\hline DAH & 135 & 4.076 & 30 & 466,50 & $14.084,71$ \\
\hline
\end{tabular}

No ano contemplado neste artigo, o departamento que ofereceu o maior número de disciplinas foi o de Artes e Humanidades (135 disciplinas), em razão do departamento possuir o maior número de cursos de graduação. Além disso, esse departamento apresentou baixo número médio de alunos por turma e menor custo médio por disciplina. $\mathrm{O}$ custo anual por disciplina entre os 
departamentos variou de $R \$ 14.084,71$ a $R \$ 117.471,17$, sendo o menor valor o do Departamento de Artes e Humanidades e o maior o do Departamento de Fitopatologia.

Os departamentos que compõem o CCA e o CCB, por possuírem maior número de laboratórios, realizarem experimentos em atividades de ensino de graduação e iniciação científica e terem grande número de aulas práticas, apresentaram custo por disciplina maior que os departamentos do CCE e CCH. É importante ressaltar que o baixo número de alunos por disciplina, apresentado por alguns departamentos, poderá contribuir para a ociosidade dos recursos existentes. Assim, é provável que os recursos como a mão de obra docente, o espaço físico das salas de aula e a energia elétrica consumida não estejam sendo aproveitados como deveriam, provocando um aumento no custo por aluno.

A partir do resultado obtido para o custo por departamento, antes da distribuição entre os mesmos, apurou-se o custo da hora/aula para os departamentos (tabela 3).

Tabela 3

Custo hora/aula do ensino de graduação em 2004

\begin{tabular}{|lccc|}
\hline Dep. & Custo sem distribuição (R\$) & Carga horária & Custo hora/aula \\
\cline { 2 - 4 } & $(\mathrm{A})$ & $(\mathrm{B})$ & $\mathrm{C}=(\mathrm{A} / \mathrm{B})$ \\
\hline DER & $2.848 .047,98$ & 4.950 & 575,36 \\
DEA & $3.179 .927,25$ & 5.700 & 557,88 \\
DEF & $3.896 .696,96$ & 6.870 & 567,20 \\
DFP & $1.527 .125,26$ & 1.755 & 870,16 \\
DFT & $5.718 .918,96$ & 8.040 & 711,31 \\
DPS & $2.347 .140,42$ & 3.960 & 592,71 \\
DZO & $4.488 .477,32$ & 5.175 & 867,34 \\
DBA & $2.963 .755,25$ & 5.325 & 556,57 \\
DBG & $2.682 .509,69$ & 5.564 & 482,12 \\
DBV & $1.771 .291,09$ & 3.615 & 489,98 \\
DBB & $1.654 .413,04$ & 3.465 & 477,46 \\
DES & $2.718 .836,17$ & 5.340 & 509,15 \\
DMB & $1.256 .540,99$ & 2.115 & 594,11 \\
DNS & $2.340 .234,20$ & 5.985 & 391,02 \\
DVT & $3.249 .354,18$ & 6.660 & 487,89 \\
DAU & $1.767 .443,58$ & 6.150 & 287,39 \\
\hline
\end{tabular}




\begin{tabular}{|lccc|}
\hline Dep. & Custo sem distribuição (R\$) & Carga horária & Custo hora/aula \\
\cline { 2 - 4 } DEC & $(\mathrm{A})$ & $(\mathrm{B})$ & $\mathrm{C}=(\mathrm{A} / \mathrm{B})$ \\
\hline DPF & $3.245 .655,71$ & 7.380 & 439,79 \\
DPI & $2.296 .933,14$ & 6.330 & 362,86 \\
DMA & $2.409 .561,03$ & 5.280 & 456,36 \\
DEQ & $2.283 .641,13$ & 7.530 & 303,27 \\
DTA & $2.747 .459,73$ & 8.310 & 330,62 \\
DEP & $3.191 .542,13$ & 7.035 & 453,67 \\
DAD & $1.030 .869,81$ & 2.250 & 458,16 \\
DPD & $2.250 .332,47$ & 4.980 & 451,87 \\
DEE & $1.607 .775,90$ & 3.930 & 409,10 \\
DED & $2.095 .011,36$ & 4.800 & 436,46 \\
DPE & $2.107 .622,75$ & 4.440 & 474,69 \\
DLA & $2.899 .233,34$ & 7.005 & 413,88 \\
DAH & $1.956 .561,98$ & 7.096 & 275,73 \\
\hline
\end{tabular}

Na tabela 3, verifica-se que o Departamento de Artes e Humanidades apresentou menor custo hora/aula (R\$249,53). Isso se deve à elevada carga horária, apresentada por esse departamento em 2004, visto que ele possui o maior número de cursos de graduação da UFV e, consequentemente, elevado número de alunos. O Departamento de Fitopatologia, em função da baixa carga horária docente, apresentou custo de $\mathrm{R} \$ 870,16$ por hora/aula, sendo o maior entre os departamentos da instituição. O Departamento de Zootecnia (DZO) também demonstrou custo por hora/aula elevado (R\$ 867,34). Esse alto custo justifica-se pela natureza das atividades desenvolvidas pelo DZO e DFT, que requerem elevado número de funcionários, laboratórios e manutenção de áreas de campo, o que requer gastos elevados.

A apuração do custo por aluno de graduação foi realizada em cada departamento. Ressalta-se que, quando o departamento oferece apenas um curso de graduação, o custo por aluno refere-se ao custo do curso ministrado, enquanto para o departamento que oferece mais de um curso, o valor é o mesmo para os diferentes cursos. A tabela 4 apresenta o custo do ensino de graduação e o custo por aluno, por departamento/curso. 
Tabela 4

Custo do ensino de graduação e custo por aluno em 2004 (R\$)

\begin{tabular}{|c|c|c|c|}
\hline Centro & Departamento & Custo da graduação & Custo por aluno \\
\hline \multirow{5}{*}{ CCA } & Economia Rural & 2.333.078,70 & $6.427,21$ \\
\hline & Engenharia Agrícola & $2.402 .352,15$ & $10.772,88$ \\
\hline & Engenharia Florestal & $4.428 .727,75$ & $13.180,74$ \\
\hline & Fitotecnia & 16.008.015,88 & $14.659,36$ \\
\hline & Zootecnia & $5.208 .972,53$ & $17.022,79$ \\
\hline \multicolumn{2}{|c|}{ Custo médio dos cursos do CCA } & & $13.095,32$ \\
\hline \multirow{5}{*}{ CCB } & Biologia Vegetal & $2.318 .685,32$ & $9.502,81$ \\
\hline & Bioquímica e Biologia Molecular & $1.220 .677,47$ & $7.978,28$ \\
\hline & Educação Física & $3.346 .430,73$ & $10.457,60$ \\
\hline & Nutrição e Saúde & 2.719.262,81 & $10.622,12$ \\
\hline & Veterinária & 4.327.780, 12 & $13.871,09$ \\
\hline \multicolumn{2}{|c|}{ Custo médio dos cursos do CCB } & & $10.842,67$ \\
\hline \multirow{8}{*}{ CCE } & Arquitetura e Urbanismo & $1.525 .992,75$ & $7.164,29$ \\
\hline & Engenharia Civil & $5.966 .972,02$ & $8.451,80$ \\
\hline & Física & $489.108,18$ & $4.253,11$ \\
\hline & Informática & $924.489,59$ & $5.282,80$ \\
\hline & Matemática & $481.728,01$ & $3.948,59$ \\
\hline & Química & $1.156 .884,30$ & $5.813,49$ \\
\hline & Tecnologia de Alimentos & $4.201 .829,36$ & $9.659,38$ \\
\hline & Engenharia Elétrica e de Produção & $2.591 .877,06$ & $7.713,92$ \\
\hline \multicolumn{2}{|c|}{ Custo médio dos cursos do CCE } & & $7.535,36$ \\
\hline \multirow{7}{*}{$\mathrm{CCH}$} & Administração & 2.247.434,94 & $4.476,96$ \\
\hline & Direito & $1.481 .416,86$ & $4.572,27$ \\
\hline & Economia & $1.216 .774,66$ & $4.269,38$ \\
\hline & Economia Doméstica & $3.175 .918,18$ & $11.806,39$ \\
\hline & Educação & $1.545 .450,33$ & $4.654,97$ \\
\hline & Letras & $1.503 .346,01$ & $4.929,00$ \\
\hline & Artes e Humanidades & $3.611 .143,00$ & $5.998,58$ \\
\hline \multicolumn{2}{|c|}{ Custo médio dos cursos do $\mathrm{CCH}$} & & $5.643,94$ \\
\hline \multicolumn{2}{|c|}{ Total/custo médio dos cursos da UFV } & $76.434 .348,72$ & $8.965,91$ \\
\hline
\end{tabular}

O custo do ensino de graduação da UFV totalizou R\$76.434.348,72 e o custo total médio por aluno foi de $\mathrm{R} \$ 8.965,91$ (tabela 4). O Departamen- 
to de Fitotecnia (DFT) apresentou maior custo para ensino de graduação ( $R$ \$ 16.008.015,88), porém não foi o departamento que teve custo por aluno mais elevado. O elevado custo deste departamento é devido ao fato de ele possuir o maior número total de docentes da UFV, cuja maioria encontra-se na categoria de adjunto, bem como o maior número de servidores técnicoadministrativos. Além disso, o DFT possui o maior número de alunos da UFV e atividades de produção (horta, pomar, cafezal etc.), o que acarretou elevado custo total. Como a maior parte dos custos dos departamentos é fixa, o elevado número de alunos apresentado por esse departamento fez com que o custo por aluno diluísse, não sendo, portanto, o mais oneroso da universidade.

O Departamento de Zootecnia apresentou o maior custo por aluno (R\$ 17.022,79) e o de Matemática o menor custo (R\$ 3.948,59). O custo por aluno de Zootecnia é 4,31 vezes mais elevado que o do curso de Matemática. Essa disparidade revela-se devido às características distintas dessas unidades de ensino. O Departamento de Zootecnia possui poucos alunos, em comparação com o quadro de servidores técnico-administrativos necessários ao funcionamento de seu curso; a sua infraestrutura pode ser considerada dispendiosa; possui alto gasto com animais destinados a experimentos; e realiza aulas práticas que requerem um gasto superior ao das aulas realizadas nas estruturas físicas da instituição. Em relação ao elevado custo do ensino do DZO ante os demais departamentos da UFV, é incontestável o elevado nível qualitativo das atividades desenvolvidas por essa unidade de ensino. Embora não esteja no escopo deste artigo, a questão da qualidade do ensino ministrado pode mais que compensar o custo incorrido.

O Departamento de Matemática, apesar de oferecer muitas disciplinas para os demais cursos da UFV, possui baixo número de alunos, assim como um quadro de pessoal docente e técnico-administrativo relativamente pequeno. Além disso, suas aulas são praticamente teóricas, com grande número de alunos, visto que oferece disciplinas para inúmeros cursos (disciplinas de massa), o que leva seus custos a se diluírem entre os demais departamentos da UFV.

O custo por aluno, apurado para os departamentos do CCA, variaram de $\mathrm{R} \$$ 6.427,21 (Departamento de Economia Rural) a R\$ 17.022,79 (Departamento de Zootecnia), sendo que o custo do curso de Zootecnia é 2,65 vezes mais elevado para a instituição do que o dos cursos existentes no Departamento de Economia Rural. A variação entre o custo por aluno entre os departamentos do CCB foi de $\mathrm{R} \$ 7.978,28$ (Curso de Bioquímica) a $\mathrm{R} \$ 13.871,09$ (Curso de Medicina Veterinária), mostrando que o Curso de Medicina Veterinária é 
1,74 vezes mais dispendioso que o de Bioquímica. O custo por aluno da área de Ciências Exatas oscilou de R \$ 3.948,59 (Departamento de Matemática) a $\mathrm{R} \$$ 9.659,38 (Departamento de Tecnologia de Alimentos), apresentando uma variação de 2,45 vezes.

Os departamentos, que compõem o Centro de Ciências Humanas, apresentaram custo semelhante por aluno, com exceção do Departamento de Economia Doméstica, que apresenta características distintas dos demais departamentos do Centro de Ciências. Esse departamento, em comparação com os outros do $\mathrm{CCH}$, é relativamente antigo, apresenta número total de docentes e técnico-administrativos superior aos demais departamentos, maior número de docentes com doutorado, alto número de laboratórios e menor quantidade de alunos de graduação. Assim, em razão de grande parte dos custos dos departamentos ser fixa, o baixo número de alunos faz com que o custo dessa unidade de ensino se eleve em relação aos demais departamentos do $\mathrm{CCH}$.

O custo total médio por aluno, apurado entre os departamentos que compõem cada centro de ciências, apresentou diferenças. O custo médio encontrado para os departamentos do CCA foi de R $\$ 13.095,32$; CCB de $\mathrm{R} \$ 10.842,67$; CCE de $\mathrm{R} \$ 7.535,36$; e CCH de $\mathrm{R} \$ 5.643,94$. Essa diferença entre o custo médio por aluno ocorre devido a fatores, tais como: número de funcionários (docentes e técnico-administrativos) existente nos departamentos de cada centro; número de alunos; a natureza das aulas de cada departamento e dos cursos que compõem os departamentos, pois em um curso que envolve muitas aulas práticas, o custo por aluno é mais elevado.

Entre os departamentos do CCA, os de Engenharia Florestal, Fitotecnia e de Zootecnia apresentam custo anual por aluno maior que o custo total médio desse centro; no CCB, apenas o Departamento de Veterinária possui custo maior que o custo total médio; no CCE, os departamentos de Tecnologia de Alimentos, de Engenharia Civil e de Engenharia Elétrica e de Produção; e no $\mathrm{CCH}$, o Departamento de Economia Doméstica apresenta custo por aluno acima do custo médio desse centro de ciências.

A partir do custo por aluno do ensino de graduação, obtido em cada departamento, foram identificados os principais fatores determinantes do resultado alcançado. Assim, procedeu-se à análise estatística das seguintes variáveis: número total de matrículas nos cursos de graduação, quantidade de funcionários (docentes e técnico-administrativos) dos departamentos, total de alunos de graduação, carga horária docente, bens móveis e área útil. A tabela 5 apresenta a análise descritiva das variáveis. 
Tabela 5

Análise descritiva das variáveis consideradas na apuração

do custo do ensino de graduação

\begin{tabular}{|lrrrccccc|}
\hline Variável & Média & $\begin{array}{c}\text { Desvio } \\
\text { padrão }\end{array}$ & Mínimo & Máximo & Assimetria & Curtose & CV \\
\hline Custo aluno (R\$) & $8.299,59$ & $3.728,87$ & $3.948,59$ & $17.022,78$ & 0,71 & $-0,37$ & 0,45 \\
№ matrículas & $3.279,60$ & $1.313,10$ & 910 & 5.860 & 0,18 & $-0,39$ & 0,40 \\
№ funcionários & 54,24 & 49,23 & 12 & 223 & 2,62 & 7,44 & 0,90 \\
№ alunos & 341,00 & 208,38 & 115 & 1.092 & 2,26 & 6,49 & 0,61 \\
Carga horária & $5.837,44$ & $1.561,46$ & 2.250 & 8.310 & $-0,42$ & $-0,40$ & 0,26 \\
Bens móveis (un) & $2.020,08$ & $1.381,46$ & 495 & 5.042 & 0,99 & 0,09 & 0,68 \\
Área útil (m $\left.{ }^{2}\right)$ & $3.540,47$ & $6.316,93$ & 259,87 & $32.226,59$ & 4,20 & 19,38 & 1,78 \\
\hline
\end{tabular}

Analisando os coeficientes de variação (CV), observa-se alta dispersão dos dados dos departamentos, relativos a funcionários, bens móveis e área útil, indicando heterogeneidade dos valores. Os valores do custo por aluno para os departamentos apresentaram coeficiente de variação de $45 \%$, o que pode ser resultante da alta variabilidade dos dados utilizados, para apurar o custo por aluno.

Após o teste das variáveis distribuídas em valores anuais para os 25 departamentos, chegou-se ao seguinte modelo:

$$
C A_{D}=9.523,475-1,358\left(N M_{G R}\right)+36,807\left(F_{D}\right)+0,611\left(B M_{D}\right)
$$

em que

$C A_{D}=$ custo anual por aluno de graduação em cada departamento;

$N M_{G R}=$ número de matrículas dos cursos de graduação, por departamento;

$F_{D}=$ número de funcionários (docentes e técnico-administrativos), por departamento;

$B M_{D}=$ total de bens móveis de cada departamento.

Entre as seis variáveis testadas, as significativas são: número de matrículas, número de funcionários (docentes e técnico-administrativos) e quantidade de bens móveis. O modelo estimado apresentou coeficiente de determinação $\left(R^{2}\right)$ de 0,8718 , revelando que $87,18 \%$ da variação no custo por aluno é explicada, conjuntamente, pelo número de matrículas, total de funcionários e número de bens móveis, ou seja, pelas variáveis incluídas no modelo. De acordo com o $\mathrm{P}$ valor encontrado para $\mathrm{F}$, a regressão existe, estatisticamente, 
a menos de 1\% de significância, indicando que, pelo menos, uma das variáveis é importante para explicar o custo por aluno.

As informações expostas, associadas à significância do teste $t$ para as variáveis, demonstram o ajustamento da regressão estimada, bem como o impacto dos regressores sobre o regressando (tabela 6).

Tabela 6

Resultado do modelo de regressão

\begin{tabular}{|lccc|}
\hline Variável & Coeficiente & $\mathrm{t}$ & $\mathrm{P}$ valor \\
\hline Custo por aluno & $9.523,475$ & 8,994 & 0,000 \\
Matrículas & $-1,358$ & $-5,763$ & 0,000 \\
Funcionários & 36,807 & 4,014 & 0,000 \\
Bens móveis & 0,611 & 1,818 & 0,083 \\
$N=25$ & $R^{2}=87,18 \%$ & $\mathrm{P}$ valor $=0,000$ & $\mathrm{a}=5 \%$ \\
\hline
\end{tabular}

As variáveis explicativas, incluídas no modelo, apresentaram coeficientes com sinais compatíveis com o esperado. Estabelecendo análise dos efeitos de cada variável do modelo no custo por aluno, mantendo as demais variáveis constantes, percebe-se que o aumento de uma unidade no número de matrículas acarretará diminuição de $\mathrm{R} \$ 1,358$ no custo por aluno; o aumento de um funcionário causará aumento de $\mathrm{R} \$ 36,807$ no custo por aluno dos departamentos e, por fim, o aumento de uma unidade no número de equipamentos, em determinado departamento, implicará elevação de $\mathrm{R} \$ 0,611$ no custo total por aluno.

Portanto, deduz-se que o aumento no número de matrículas acarretará diminuição no custo por aluno; o aumento no número de docentes e servidores técnico-administrativos implicará aumento do custo por aluno; e o aumento no número de bens móveis elevará o custo por aluno.

No que se refere à variável funcionário, o aumento no quadro de pessoal provocará elevação no seu gasto, tornando-se necessário aumento no número de equipamentos para dar condições apropriadas à realização de suas atividades.

É importante destacar que há grande proporção de custos fixos nos departamentos da UFV, visto que a maior composição dos custos dos órgãos administrativos e acadêmicos, que constituem a estrutura da instituição, é o gasto com pessoal. Essa realidade é semelhante à de outras instituições federais de ensino, pois, segundo Peter e colaboradores (2003), a maior parcela dos custos das universidades federais é de custos fixos. Assim, a redução no número de matrículas pode resultar em elevação de capacidade ociosa, por não otimizar a estrutura e os recursos existentes nessas Ifes. 
Como um departamento oferece disciplinas para alunos que pertencem a outro departamento, parte dos custos fixos é distribuída ente as unidades de ensino, diluindo, assim, o custo por aluno. Nesse caso, os departamentos que ofertam parte de sua capacidade instalada a outro estão otimizando sua estrutura física.

As experiências de apuração de custo, no Brasil, apresentam resultados diferentes de custo por aluno, quando comparados aos custos obtidos aqui. A pesquisa desenvolvida por Morgan (2004), na Universidade de Brasília, mostrou que, em média, o custo por aluno na instituição, objeto de estudo em 2003, era de $R \$ 5.187,00$, enquanto na UFV esse custo atingiu o valor de R\$ 8.965,91 (2004). Amaral (2005), apurando o custo médio por aluno das Ifes, em 1997, encontrou o valor de $\mathrm{R} \$ 5.482,00$, enquanto o custo por aluno foi de $\mathrm{R} \$ 5.873,00$ para a UFV.

Tomando os resultados deste artigo como base e assumindo os valores relativos a 2004 como constantes, estimou-se o gasto total médio da formação do aluno, considerando a duração padrão de cada curso, conforme tabela 7.

Tabela 7

\section{Custo total médio da formação dos alunos dos cursos de graduação}

\begin{tabular}{|clccc|}
\hline Dep. & Cursos de graduação & $\begin{array}{c}\text { Duração } \\
\text { padrão }\end{array}$ & $\begin{array}{c}\text { Custo aluno } \\
\text { (R\$) }\end{array}$ & $\begin{array}{c}\text { Custo médio da formação } \\
\text { (R\$) }\end{array}$ \\
\hline DER & Gestão de Cooperativas & 4 & $6.427,21$ & $25.708,86$ \\
& Gestão do Agronegócio & 4,5 & $6.427,21$ & $28.922,46$ \\
DEA & Engenharia Agrícola & 5 & $10.772,88$ & $53.864,40$ \\
DEF & Engenharia Florestal & 4,5 & $13.180,74$ & $59.313,32$ \\
DFT & Agronomia & 5 & $14.659,36$ & $73.296,78$ \\
DZO & Zootecnia & 4,5 & $17.022,79$ & $76.602,54$ \\
DBV & Ciências Biológicas & 4,5 & $9.502,81$ & $42.762,64$ \\
DBB & Bioquímica & 4,5 & $7.978,28$ & $35.902,28$ \\
DES & Educação Física & 4 & $10.457,60$ & $41.830,38$ \\
DNS & Nutrição e Saúde & 4 & $10.622,12$ & $42.488,48$ \\
DVT & Medicina Veterinária & 5 & $13.871,09$ & $69.355,45$ \\
DAU & Arquitetura e Urbanismo & 5 & $7.164,29$ & $35.821,43$ \\
DEC & Engenharia Ambiental & 5 & $8.451,80$ & $42.259,01$ \\
& Engenharia Civil & 5 & $8.451,80$ & $42.259,01$ \\
& Engenharia Agrimensura & 5 & $8.451,80$ & $42.259,01$ \\
DPF & Física & 4 & $4.253,11$ & $17.012,46$ \\
\hline
\end{tabular}




\begin{tabular}{|llccc|}
\hline Dep. & Cursos de graduação & $\begin{array}{c}\text { Duração } \\
\text { padrão }\end{array}$ & $\begin{array}{c}\text { Custo aluno } \\
(\mathrm{R} \$)\end{array}$ & $\begin{array}{c}\text { Custo médio da formação } \\
\text { (R\$) }\end{array}$ \\
\hline DPI & Ciência da Computação & 4 & $5.282,80$ & $21.131,19$ \\
DMA & Matemática & 4 & $3.948,59$ & $15.794,36$ \\
DEQ & Química & 4 & $5.813,49$ & $23.253,96$ \\
DTA & Ciência e Tecnologia de & 4 & $9.659,38$ & $38.637,51$ \\
& Laticínios & & & \\
& Engenharia de Alimentos & 5 & $9.659,38$ & $48.296,89$ \\
DEP & Engenharia Elétrica & 5 & $7.713,92$ & $38.569,60$ \\
& Engenharia de Produção & 4,5 & $7.713,92$ & $34.712,64$ \\
DAD & Administração & 4,5 & $4.476,96$ & $20.146,33$ \\
& Ciências Contábeis & 4,5 & $4.476,96$ & $20.146,33$ \\
DPD & Direito & 5 & $4.572,27$ & $22.861,37$ \\
DEE & Economia & 4,5 & $4.269,38$ & $19.212,23$ \\
DED & Economia Doméstica & 4 & $11.806,39$ & $47.225,55$ \\
DPE & Pedagogia & 4 & $4.654,97$ & $18.619,88$ \\
DLA & Letras & 4 & $4.929,00$ & $19.716,01$ \\
& Secretariado Executivo & 4,5 & $4.929,00$ & $22.180,51$ \\
& Trilíngue & & & $23.994,31$ \\
DAH & Comunicação Social & 4 & $5.998,58$ & $23.994,31$ \\
& História & 4 & $5.998,58$ & $23.994,31$ \\
& Dança & $4.993,59$ \\
& Geografia & $5.998,58$ & \\
\hline
\end{tabular}

Na tabela 7, observa-se que a duração padrão dos cursos de graduação é de 4, 4,5 e 5 anos. O curso de Zootecnia apresenta custo médio de $\mathrm{R} \$ 76.602,54$ para formação do aluno, o maior entre os departamentos da UFV. Entretanto, o Departamento de Matemática, se os alunos se formarem no período padrão, gastará $\mathrm{R} \$ 15.794,36$, em média. Assim, os departamentos que têm maior custo por aluno são os que possuem maior número de funcionários, laboratórios e atividades práticas.

Considerando o período médio de titulação em cada curso e o resultado obtido, constata-se que cursos com diferente duração apresentam custo de formação semelhante, como é o caso dos cursos de Secretariado Executivo Trilíngue e Direito, que apresentam duração média de 4,5 e 5 anos e custo médio total de $\mathrm{R} \$ 22.180,51$ e $\mathrm{R} \$ 22.861,37$, respectivamente. Além disso, 
podem ser identificados cursos com mesma duração média, que apresentam custo médio de formação bastante diferente como os cursos de Agronomia e de Direito que apresentam duração padrão de cinco anos e custo médio de formação de $\mathrm{R} \$ 73.296,78$ e $\mathrm{R} \$ 22.861,37$, respectivamente. No primeiro caso, as estruturas dos cursos com maior número de atividades em salas de aula são semelhantes. No segundo caso, as estruturas dos cursos são bastante diferentes. Assim, as semelhanças e divergências entre os custos se justificam em razão das diferentes estruturas.

Segundo Amaral (2005), realizar comparação entre o custo por aluno de diferentes instituições ou entre níveis de ensino é difícil, em função das especificidades de cada universidade e da heterogeneidade de seus alunos. Constata-se que isso não é diferente quando se pretende comparar o custo por aluno dos cursos existentes nos diversos departamentos de determinada instituição, visto que eles também possuem características distintas. Por exemplo, existem departamentos que oferecem somente cursos de graduação, enquanto em outros o enfoque é a pós-graduação. Além disso, há departamentos que apresentam um quadro de pessoal altamente titulado, sendo que outros ainda estão promovendo a qualificação de seus docentes.

\section{Conclusões}

No atual cenário político nacional, há incentivos para a expansão das universidades federais em função do atual processo de distribuição de recursos. Essa expansão pode ser tanto interna (criação de novos cursos e/ou abertura de novas vagas em cursos existentes) quanto externa (criação de novos campi). A expansão interna dessas instituições, no caso específico da UFV, pode contribuir para uma diluição dos custos fixos, acarretando redução no custo por aluno. Entretanto, uma expansão externa pode resultar em elevação do custo na instituição, pois requererá a contratação de novos docentes e servidores técnico-administrativos, investimentos em máquinas, equipamentos e infraestrutura em geral.

O aumento do número de vagas na UFV, por meio de expansão interna, será vantajoso até certo nível. O limite de crescimento seria aquele que otimizasse a capacidade instalada da instituição, ou seja, o uso dos recursos existentes (pessoal, estrutura física), pois ultrapassada essa capacidade, incorre-se em aumento da demanda por mais funcionários (docentes e técnicos), equipamentos, salas de aula, laboratórios etc. 
Ainda no que se refere à expansão de vagas na UFV, caso a dotação orçamentária permaneça inalterada ou ocorra pequena elevação, entende-se que a melhor alternativa de expansão no número de vagas seria nos cursos que apresentam menor custo por aluno, bem como nos cursos que possuem capacidade ociosa. Nesse caso, os cursos que apresentam menor custo são aqueles que possuem maior número de aulas teóricas, visto que estas são menos onerosas para a instituição do que as aulas práticas. Entretanto, para expandir vagas deve-se analisar se os cursos que apresentam menor custo por aluno atendem à demanda da sociedade por profissionais, assim como às necessidades de mercado.

Cabe ressaltar que os resultados encontrados não podem ser generalizados para outras Ifes, pois é um estudo de caso, e outras instituições apresentam realidades diferentes e características específicas. Assim, sugere-se que sejam realizadas pesquisas em outras Ifes, para verificar se as variáveis que compõem o custo por aluno na UFV são semelhantes às demais instituições de ensino. Recomenda-se que os esforços das pesquisas sejam utilizados pelos gestores de recursos públicos para o desenvolvimento de modelos e seu aprimoramento, visando à otimização no uso desses recursos e à efetiva contribuição para melhoria do bem-estar da sociedade brasileira.

Este artigo pode ser considerado um avanço no que diz respeito à mensuração de custos em instituições federais de ensino superior. A apuração do custo por aluno de uma instituição de ensino consiste em importante contribuição para superar as dificuldades de controle de custos do setor educacional.

\section{Referências}

AMARAL, Nelson Cardoso. Evolução do custo do aluno das Ifes: eficiência. 2005. Disponível em: <www.anped.org.br/26/trabalhos/nelsoncardosoamaral.doc>. Acesso em: 23 out. 2005.

BRASIL. Tribunal de Contas da União. Orientação para o cálculo dos indicadores de gestão. Decisão TCU n. 408/2002 — Plenário. 2005. Disponível em: <www.uff. br/catalogo/document/pdf/indicado.pdf>. Acesso em: 25 jul. 2006.

CREPALDI, Silvio Aparecido. Contabilidade gerencial. 2. ed. São Paulo: Atlas, 2002. GIL, Antonio Carlos. Como elaborar projeto de pesquisa. 3. ed. São Paulo: Atlas, 1996. HANSEN, Don R.; MOWEN, Maryanne M. Gestão de custos: contabilidade e controle. Tradução Robert Brian Taylor. 3. ed. São Paulo: Thomson, 2003. 
HORNGREN, Charles T.; FOSTER, George; DATAR, Srikant. M. Contabilidade de custos. 9. ed. Rio de Janeiro: LTC, 2000.

KOSHAL, Rajindar K.; KOSHAL, Manjulika. Economies of scale and scope in higher education: a case of comprehensive universities. Economics of Education Review, ElsevierScience, v. 18, p. 269-277, 1999.

LEONE, George Guerra. Custos: um enfoque administrativo. 14. ed. Rio de Janeiro: FGV, 2001.

MAHER, Michael. Contabilidade de custos: criando valor para o administrador. Tradução de José Evaristo dos Santos. São Paulo: Atlas, 2001.

MORGAN, Beatriz Fátima. A determinação do custo do ensino na educação superior: o caso da Universidade de Brasília. 2004. 161 f. Dissertação (Mestrado em Ciências Contábeis) - Universidade de Brasília, Brasília, Distrito Federal. Disponível em: <www.unb.br/face/Disserta_Beatriz_Fatima.pdf>. Acesso em: 20 jun. 2005.

PETER, Maria da Glória Arrais et al. Proposta de um sistema de custos para as universidades federais brasileiras fundamentado no activity based costing. In: ENCONTRO NACIONAL DOS PROGRAMAS DE PÓS-GRADUAÇÃO EM ADMINISTRAÇÃO, 2003. Anais eletrônicos... Atibaia, São Paulo: Enanpad, 2003.

REINERT, José Nilson; REINERT, Clio. Método ABCD: universidade para apuração de custos de ensino em instituições federais de ensino superior. In: CONGRESSO INTERNACIONAL DE CUSTOS. 9., 2005. Anais eletrônicos... Florianópolis, 2005. CD-ROM.

ROSA, Paulo Moreira da. Proposta de modelo de gestão por atividades para universidades públicas brasileiras. 2004. 227 f. Tese (Doutorado em Engenharia de Produção) - Universidade Federal de Santa Catarina, Florianópolis. Disponível em: <www. ufsc.br>. Acesso em: 21 jun. 2006.

SILVA, César Augusto Tibúrcio; MORGAN, Beatriz Fátima; COSTA, Patrícia de Souza. Apuração do custo de ensino por aluno: aplicação a uma instituição federal de ensino superior. In: ENCONTRO NACIONAL DOS PROGRAMAS DE PÓS-GRADUAÇÃO EM ADMINISTRAÇÃO. Anais eletrônicos... Curitiba, Paraná: Enanpad, 2004. CD-ROM.

UFV. Universidade Federal de Viçosa. UFV em números - 2005. Viçosa, Minas Gerais. Disponível em: <www.ufv.br/proplan/ufvnumeros/numeros2005.pdf>. Acesso em: 14 ago. 2006.

VERGARA, Sylvia Constant. Projetos e relatórios de pesquisa em administração. 6. ed. São Paulo: Atlas, 2005.

YIN, Robert K. Estudo de caso: planejamento e métodos. 2. ed. Porto Alegre: Bookman, 2001. 